secondary attack was higher than expected. ${ }^{25}$ Household contacts of a patient had a relative risk of infection 750 times that of other people in the health district $(1 \cdot 94 / 0 \cdot 0026)$. Possibly the rate of secondary attack would have been higher still without prophylaxis. Possibly, too, prophylaxis did not reduce rates of attack but merely delayed the onset of secondary cases in the family; the three patients whose families received "complete" prophylaxis developed the disease more than three months later. Successful eradication of carriage within the household cannot prevent outbreak strains re-entering the family; the interval depends on the prevalence and rate of transmission of outbreak strains in the local population.

Whether or not prophylaxis has been given the general practitioner and members of the family should remain vigilant after a case of meningococcal disease. A randomised controlled trial is needed to test the hypothesis that eradicating meningococcal carriage in household contacts prevents further cases of meningococcal disease.

This study was supported financially by the Department of Health and Social Security. We thank Drs Dennis Jones and Stephen Palmer for their constructive comments on this paper and the staff of the public health laboratories in Gloucester and Manchester for technical help.

1 Public Health Laboratory Service Communicable Disease Surveillance Centre. Report. Br Med f 1986;292:1447-8.

2 Centers for Disease Control. Analysis of endemic meningococcal disease by serogroup and evaluation of chemoprophylaxis. I Infect Dis 1976;134:201-4. 3 Broome CJ. The carrier state: Neisseria meningitidis. $f$ Antimicrob Chemother 1986; 18 (suppl A):25-34

+ Cartwright KAV, Stuart JM, Jones DM, Noah ND. The Stonehouse survey: nasopharyngeal carriage of meningococci and Neisseria lactamica. Epidemiol Infect 1987;99:591-601.

5 De Wals P, Hertoghe L, Bortee-Grimee I, et al. Meningococcal disease in Belgium. Secondary attack rate among household, day care nursery and preelementary school contacts. J Infect 1981;3(suppl 1):53-61.

Accepted 21 December 1988)

\section{Nicotine absorption and dependence in an over the counter aid to stopping smoking}

\author{
Michael Belcher, Martin J Jarvis, \\ Gay Sutherland
}

Imperial Cancer Research Fund Health Behaviour Unit, Institute of Psychiatry, London SE5 8AF

Michael Belcher, RMN, clinical nurse specialist Martin J Jarvis, MPHIL, senior lecturer

Addiction Research Unit, Institute of Psychiatry, London SE5 8AF

Gay Sutherland, MPHIL, clinical psychologist

Correspondence to: Mr Belcher.

BrMed f 1989;298:570
The importance of nicotine dependence in cigarette smoking and as a deterrent to stopping is receiving increasing recognition. ${ }^{.}$This stems partly from the use of nicotine replacement methods to treat dependent smokers. Nicotine chewing gum, available only on prescription, is the only nicotine replacement treatment that is licensed in the United Kingdom. We investigated the absorption of nicotine from an over the counter aid to stopping smoking (Stoppers; Leo Laboratories).

\section{Case report and study}

A 38 year old man who had smoked hand rolled cigarettes for over 20 years stopped smoking with the help of nicotine chewing gum (Nicorette) $2 \mathrm{mg}$ from his general practitioner. After he had used 15 pieces a day for two months he broke a tooth while chewing. He then started taking Stoppers, describing the transition as effortless, and was soon taking 30-60 lozenges a day. He contacted our clinic after a failed attempt to stop them after two years' use. Stopping taking Stoppers had resulted in his feeling irritable, ill at ease, unable to concentrate, depressed, and hungrier than usual. These symptoms of withdrawal from tobacco were rapidly relieved when he resumed taking Stoppers after four days' abstinence. We took a blood sample just after he had finished one lozenge, after a total of 20 on the day. Plasma nicotine and cotinine concentrations were $18.9 \mu \mathrm{g} / \mathrm{l}$ and $415 \mu \mathrm{g} / 1$ respectively. An expired air carbon monoxide concentration of $3 \mathrm{ppm}$ confirmed that he had stopped smoking.

He bought his lozenges in bulk from the manufacturer, partly for economic reasons as a discount was offered and partly because of anxiety about running out. He also believed that these lozenges were stronger and more satisfying than lozenges purchased from pharmacists.

We tested lozenges obtained from local pharmacists and directly from the manufacturer. Four volunteers who no longer smoked took lozenges from both sources on a schedule of two every 30 minutes and allowed them to dissolve without sucking. Subjects were meant to take 28 lozenges over seven hours but some stopped before this because of nausea. Blood samples for analysis of nicotine concentrations were taken 30 minutes after the last dose. The mean plasma nicotine concentration achieved with supplies bought from a pharmacist was $14.6 \mu \mathrm{g} / \mathrm{l}$ after an average of 22 lozenges taken over five and a half hours. The mean concentration achieved with lozenges supplied by the factory was $22.3 \mu \mathrm{g} / \mathrm{l}$ after an average of 17 lozenges over four hours. The plasma nicotine concentration increased by a mean of $4.6 \mu \mathrm{g} / \mathrm{l}$ (range $3 \cdot 6-5 \cdot 2$ ) over 30 minutes in three subjects who took two lozenges supplied by the factory.

\section{Comment}

Stoppers led to substantial absorption of nicotine. The concentrations from lozenges bought locally were higher than those from clinical use of $2 \mathrm{mg}$ nicotine chewing gum, ${ }^{2}$ whereas lozenges supplied by the factory gave concentrations similar to the lowest achieved from cigarette smoking ${ }^{2}$ and to those achieved from chewing $4 \mathrm{mg}$ gum on an imposed schedule. ${ }^{34}$ Absorption from two lozenges was roughly similar to that from one piece of $2 \mathrm{mg} \mathrm{gum} .^{5}$ The factory lozenges delivered more nicotine than those bought locally, confirming reports from patients and suggesting that the product may have a limited shelf life.

Our observations suggest that Stoppers have some therapeutic potential as a specific effect of nicotine in alleviating withdrawal from tobacco and promoting stopping smoking is now well established. The ease of taking the lozenges may make them suitable for dependent smokers who find chewing gum difficult or aversive. At the same time, there must be concern about the lack of information and guidance provided for the consumer and about the potential for abuse. The lozenges are not packaged in child proof containers, and the labelling does not mention nicotine, say why nicotine might be helpful, or point out any hazards of use.

1 United States Department of Health and Human Services. Nicotine addiction: report of the surgeon general. Rockville: USDHSS, 1988.

2 West RJ, Jarvis MJ, Russell MAH, Carruthers ME, Feyerabend C. Effect of nicotine on the cigarette withdrawal syndrome. Br f Addict 1984;79:215-9.

3 Russell MAH, Sutton SR, Feyerabend C, Cole PV, Saloojee Y. Nicotine hewing

$4 \mathrm{McNabb}$ ME, Ebert RV, McCusker K. Plasma nicotine levels produced by chewing nicotine gum. FAMA 1982;248:865-8.

5 Benowitz NL, Jacob P, Savanapridi C. Determinants of nicotine intake whil chewing nicotine polacrilex gum. Clin Pharmacol Ther 1987;41:467-73.

(Accepted 12 December 1988

I

